\title{
A Hypoechoic Lesion in Liver: A Rare Presentation of Liver Abscess
}

\section{Ramanuj Mukherjee* and Sudipta Samanta}

Department of Surgery, India

Received: 制: December 17, 2018; Published: ㄴㅔㅛ: January 03, 2019

*Corresponding author: Ramanuj Mukherjee, Department of Surgery, India

\section{Introduction}

A 35-year-old gentleman presented with a complaint of hemoptysis for last 1 month and fever for last 2 days. He complained occasional pain in the right upper quadrant of the abdomen. On examination a lump has been noted in the right flank which appeared to be soft, fluctuant, non-tender (Figures 1 \& 2). The lump was not pulsatile but was slightly moving with respiration. On investigation by a CECT abdomen (Figure 1) a hypoechoic lesion in the right lobe of liver was found which was communicating beneath the skin. A diagnosis of amebic liver abscess was made. On aspirating the abscess anchovy-sauce like pus was obtained. However, the pus was sterile i.e. no trophozoite or cyst was found. He received metronidazole and the pus was aspirated and drained.
Amebic liver abscess can very rarely present in such a fashion. If it presents in such a fashion a provisional diagnosis can be made from CT scan since it doesn't contain any septation and has a thickened wall. The characteristic pus is anchovy-sauce colored. The possible explanation of hemoptysis is rupture is a broncho-hepatic fistula. Other modalities that could be used for diagnosing amebic liver abscess can be serological testing of antiamebic antibodies in serum.1 The drawback of estimating antibodies against total amebic antigen is that in a highly endemic area often patients may remain seropositive for years after infection and antibody response to Gal/GalNAc adherence lectin, on contrary, is much shorter lived and present in acute amebiasis [1]

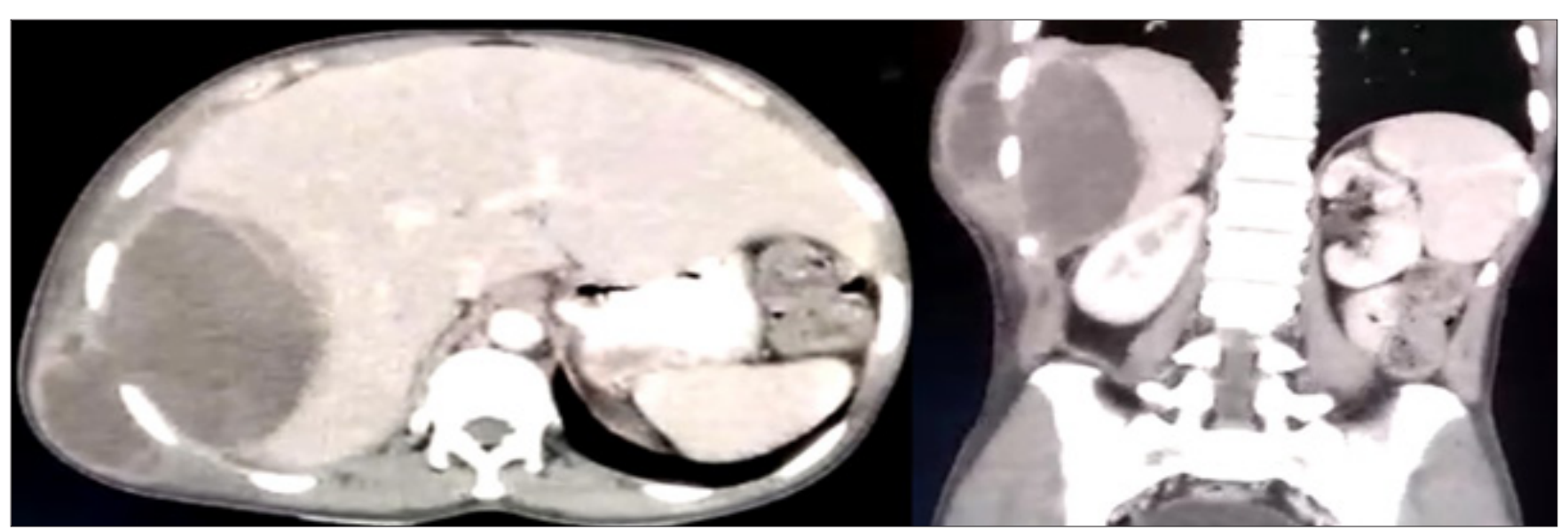

Figure 1: CECT Abdomen showing a hypoechoic lesion in the right lobe of liver communication beneath the skin. (Left hand side shows transverse section and right hand side shows coronal section of abdomen). 


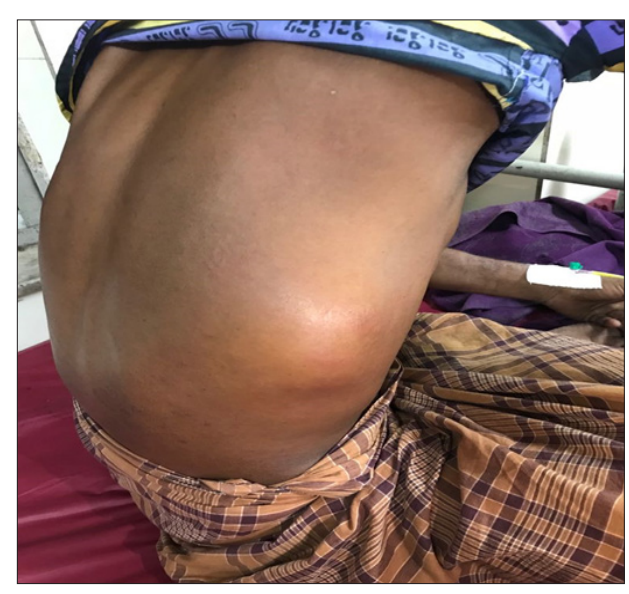

Figure 2: A soft, fluctuant, non-tender lump in the right flank.

ISSN: 2574-1241

DOI: 10.26717/BJSTR.2019.12.002291

Ramanuj Mukherjee. Biomed J Sci \& Tech Res

(c) (i) This work is licensed under Creative

Submission Link: https://biomedres.us/submit-manuscript.php

\section{References}

1. Haque R, Mollah NU, Ali IK, Alam K, Eubanks A, et al. (2000) Diagnosis of Amebic Liver abscess and intestinal infection with the TechLab Entamoeba histolytica II antigen detection and antibody tests. J Clin Microbiol 38(9): 3235-3239.

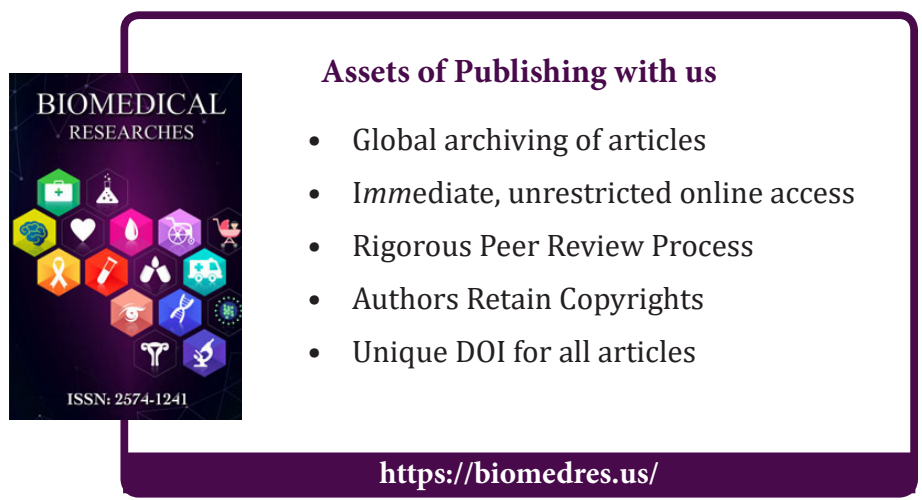

